\title{
演題番号 3
}

\section{プロタミン必要量レプロタミン概算量の比較検討}

神奈川県立こどあ医療センター 麻酔科 $\mathrm{M} \mathrm{E}$

藤島良一 周 藤 博 隆

同 麻酔科

緒 方 健一深 津修

同 胸部外科

長田信洋大川恭矩伊藤健二

\section{はじめに}

体外循環を行なうに際し，抗凝固剤としてのへ パリンと，その中和を目的とするプロタミンは欠 くことのできない薬剤である。特にプロタミンは, 多量に使用した場合，心拍数低下，血圧低下，血 小板数减少，血液凝固時間の延長などの悪影響を 生じやすいという報告が多々ある。当施設では， ヘパリンとプロタミンの適正投与につい 1979 年 1 月のてよ゙も医療センタ一医学誌, 第 8 巻, 第 1 号にて研究発表し, 現在行なわれている投与方法, 投与量については確立していると考えている.

今回我々は，体外循環終了直後へパリンを中和 し，早期止血目的のために静注投与しているプロ タミン概算量とプロタミン必要量について比較検 討し, 新たなプロタミン概算量を算出し再検討し た.

\section{対象およぴヘパリン, プロタミン使用状況}

対象は, 1986年1月〜 1987年 2 月までの当施設 で行なわれた開心術症例 120例である.

年齢は 0 日〜 180 月, 平均 $49.47 \pm 42.97$ 月, 体 重は $2.4 \mathrm{~kg} \sim 76.4 \mathrm{~kg}$, 平均 $14.40 \pm 10.49 \mathrm{~kg}$ であっ た.

ヘパリン使用状況

1) 送脱血力ニューレ㨂入直前に $2 \mathrm{mg} / \mathrm{kg}$ 静注

2）体外循環 1 時間毎に $1 \mathrm{mg} / \mathrm{kg}$ 追加投与

3）充填時血液 $200 \mathrm{~m} \ell$ につ $5 \mathrm{mg}$ 添加
4）無血充填時は $500 \mathrm{mllつき} 10 \mathrm{mg}$ 添加 プロタミン使用状況

1) 体外循環終了直後概算量

2) プロタミン必要量から概算量を引いた残量 を追加投与

\section{目的および方法}

120 症例に対し

1）体外循環時間 6 群

2) 充填時使用血液量 6 群

3) 体重 4 群

各群に分け, 現在行なわれているプロタミン概 算量〔ヘパリン使用総量 $\times 33 \%$ とプロタミン必

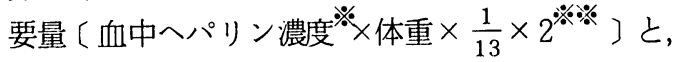
新たに算出したプロタミン概算量〔へパリン使用 総量 $\times 50 \%$ Jの 3 項目平均 $\pm S D$ 值についての比 較検討を行なった。

結 果

\section{体外循環時間群}

体外循環時間， 6 群の月齢，体重，体外循環時 間，ヘパリンのkg当の量，プロタミン必要量のkg 当の量, プロタミン・ヘパリンの使用総量比, プ ロタミン概算量 33\%のkg当の量, プロタミン概算 量50\%のkg当の量である (表 1 ).

※ 図 1 を参照

※ 図2 を参照 
体外循環持間, 6群のプロタミン必要量に対し ての $33 \%$ 概算量. $50 \%$ 概算量の平均值でのグラフ である(図 3 ).

Student $\mathrm{T}$ test では,

33\%概算量と必要量 $55 \%$ 概算量と必要量

I群 有意差有 $(\mathrm{P}<0.01)$ 有意差有 $(\mathrm{P}<0.01)$

II群 有意差有 $(\mathrm{P}<0.01)$ 有意差有 $(\mathrm{P}<0.01)$

收群 有意差有 $(\mathrm{P}<0.01)$ 有意差 無 $(\mathrm{P}<0.01)$

IV 群 有意差有 $(P<0.01)$ 有意差 無 $(P<0.01)$

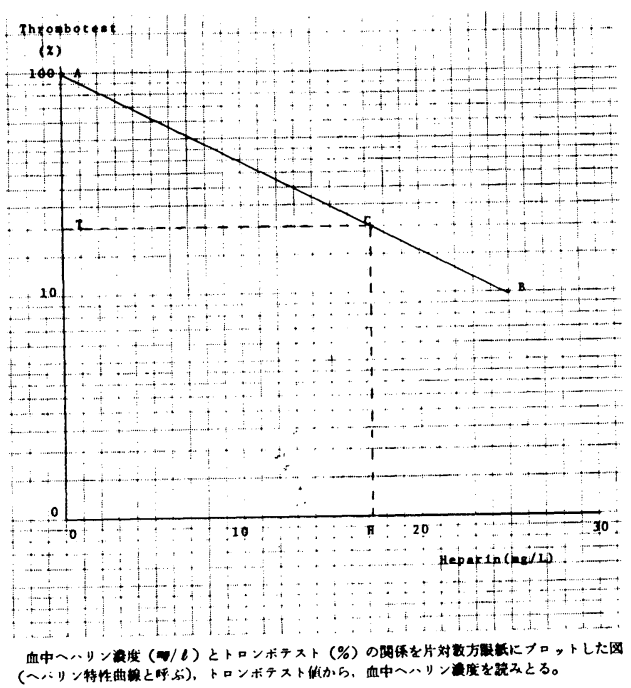

図1 血中ヘパリン濃度については 当施設での 方法で，トロンボテストによるヘパリン特 性曲線にて算出.
$V$ 群 有意差無 $(P<0.01)$ 有意差 無 $(P<0.01)$

VI群 有意差有 $(\mathrm{P}<0.01)$ 有意差 無 $(\mathrm{P}<0.01)$ のようになった。

Thrombotest

(sec.)

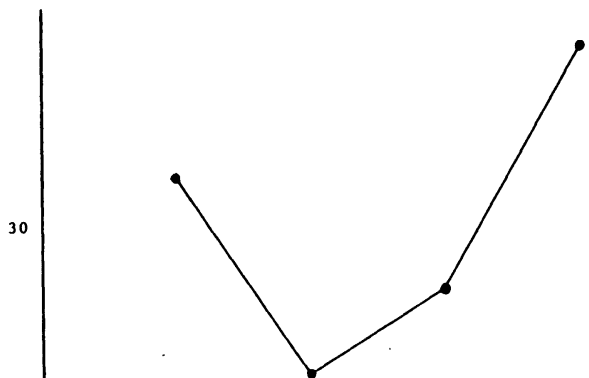

20

1

2

Protamine/Heparin ratio

ブロタミン対へハリン血中濃度比とトロン ボテスト（秒）の耑係。濃度比 2 でへハリン 中和効果か取人である

図2 プロタミン対ヘパリン血中濃度比とトロン ボテスト (秒) の関係で湿度比が 2 でヘパ リン中和効果が最大である.

表 1 T IME群

\begin{tabular}{|c|c|c|c|c|c|c|c|c|c|c|}
\hline & e & 月 & $\begin{array}{c}\mathrm{kg} \\
\text { 体直 }\end{array}$ & $\begin{array}{c}\text { 分 } \\
\text { 体外循環時間 }\end{array}$ & $\begin{array}{c}\mathrm{mg} / \mathrm{kg} \text { 当 } \\
\text { Heparin }\end{array}$ & $\begin{array}{l}\mathrm{mg} / \mathrm{kg} \text { 当 } \\
\text { Protamin }\end{array}$ & $\mathrm{P} / \mathrm{H}$ 比 & \begin{tabular}{|l|}
$\mathrm{mg} / \mathrm{kg}$ 当 \\
$\mathrm{P} / \mathrm{H} 33 \%$
\end{tabular} & $\begin{array}{l}\mathrm{mg} / \mathrm{kg} \text { 当 } \\
\mathrm{P} / \mathrm{H} 50 \%\end{array}$ & 䛧 項 \\
\hline$I_{n=23}$ & 年下 & $\begin{array}{r}71.83 \\
\pm 36.12 \\
\end{array}$ & $\begin{array}{r}18.75 \\
\pm 8.03 \\
\end{array}$ & $\begin{array}{l}18.48 \\
\pm 4.98\end{array}$ & $\begin{array}{c}3.21 \\
\pm 0.35\end{array}$ & $\begin{array}{c}2.39 \\
\pm 0.73\end{array}$ & $\begin{array}{c}0.76 \\
\pm 0.26\end{array}$ & $\begin{array}{c}1.10 \\
\pm 0.22\end{array}$ & $\begin{array}{c}1.61 \\
\pm 0.18\end{array}$ & \begin{tabular}{|c|}
$\mathrm{P} / \mathrm{H} 76 \%$ \\
2.44 \\
\pm 0.27 \\
\end{tabular} \\
\hline II $_{n=27}$ & $\int_{60 \text { 分 }}^{31 \text { 分 }}$ & $\begin{array}{c}53.63 \\
\pm 40.00\end{array}$ & $\begin{array}{c}16.65 \\
\pm 13.48\end{array}$ & $\begin{array}{l}45.22 \\
\pm 8.35\end{array}$ & $\begin{array}{c}3.62 \\
\pm 0.71\end{array}$ & $\begin{array}{c}2.36 \\
\pm 0.60\end{array}$ & $\begin{array}{c}0.68 \\
\pm 0.24\end{array}$ & $\begin{array}{c}1.20 \\
\pm 0.23\end{array}$ & $\begin{array}{l}1.85 \\
\pm 0.37\end{array}$ & $\begin{array}{c}P / H \text {. } 68 \% \\
2.46 \\
\pm 0.48 \\
\end{array}$ \\
\hline${ }^{\text {III }}=23$ & $\int_{90 \text { 分 }}^{61 \text { 分 }}$ & $\begin{array}{c}40.13 \\
\pm 40.38\end{array}$ & $\begin{array}{r}13.38 \\
\pm 12.97 \\
\end{array}$ & $\begin{array}{c}75.09 \\
\pm 10.32\end{array}$ & $\begin{array}{l}4.75 \\
\pm 1.62\end{array}$ & $\begin{array}{l}2.30 \\
\pm 0.56\end{array}$ & $\begin{array}{c}0.52 \\
\pm 0.20\end{array}$ & $\begin{array}{r}1.57 \\
\pm 0.53 \\
\end{array}$ & $\begin{array}{c}2.38 \\
\pm 0.79\end{array}$ & \begin{tabular}{|c|} 
P/H $52 \%$ \\
2.47 \\
\pm 0.84 \\
\end{tabular} \\
\hline $\begin{array}{l}\text { IV } \\
n=22\end{array}$ & $\int_{120 \text { 分 }}^{91 \text { 分 }}$ & $\begin{array}{c}26.63 \\
\pm 29.44\end{array}$ & $\begin{array}{l}9.31 \\
\pm 4.73\end{array}$ & $\begin{array}{l}106.32 \\
\pm 9.44\end{array}$ & $\begin{array}{r}6.40 \\
\pm 2.11 \\
\end{array}$ & $\begin{array}{c}2.99 \\
\pm 0.87 \\
\end{array}$ & $\begin{array}{c}0.49 \\
\pm 0.12\end{array}$ & $\begin{array}{l}2.12 \\
\pm 0.70\end{array}$ & $\begin{array}{l}3.20 \\
\pm 1.04\end{array}$ & $\begin{array}{c}\mathrm{P} / \mathrm{H} \quad 49 \% \\
3.14 \\
\pm 1.03 \\
\end{array}$ \\
\hline $\begin{array}{l}V \\
n=16\end{array}$ & $\int_{180 \text { 分 }}^{121 \text { 分 }}$ & $\begin{array}{c}35.75 \\
\pm 43.71\end{array}$ & $\begin{array}{l}10.41 \\
\pm 7.03\end{array}$ & $\begin{array}{r}139.25 \\
\pm 13.31\end{array}$ & $\begin{array}{l}7.30 \\
\pm 3.50\end{array}$ & $\begin{array}{l}2.78 \\
\pm 1.04\end{array}$ & $\begin{array}{c}0.43 \\
\pm 0.18\end{array}$ & $\begin{array}{l}2.41 \\
\pm 1.15\end{array}$ & $\begin{array}{l}3.65 \\
\pm 1.75\end{array}$ & $\begin{array}{c}\mathrm{P} / \mathrm{H} \quad 43 \% \\
3.29 \\
\pm \mathrm{i} .58 \\
\end{array}$ \\
\hline $\begin{array}{l}\text { VI } \\
n=9\end{array}$ & $\begin{array}{l}\text { 181分 } \\
\text { 以上 }\end{array}$ & $\begin{array}{c}83.89 \\
\pm 58.17\end{array}$ & $\begin{array}{l}18.69 \\
\pm 7.51\end{array}$ & $\begin{array}{l}288.22 \\
\pm 98.97\end{array}$ & $\begin{array}{c}5.95 \\
\pm 0.41\end{array}$ & $\begin{array}{c}3.21 \\
\pm 1.05\end{array}$ & $\begin{array}{c}0.54 \\
\pm 0.17\end{array}$ & $\begin{array}{c}1.96 \\
\pm 0.13\end{array}$ & $\begin{array}{c}2.93 \\
\pm 0.34\end{array}$ & $\begin{array}{c}\mathrm{P} / \mathrm{H} 54 \% \\
3.21 \\
\pm 0.22 \\
\end{array}$ \\
\hline
\end{tabular}






\section{充垣時使用血夜量群}

表 2 は充填時使用血液量 6 群の表である。内容 は, 体外循環時間群表 1 と同様である.

充填時使用血液量 6 群のプロタミン必要量に対 しての33\%概算量, $50 \%$ 概算量の平均值でのグラ フである(図 4).

Studen $\mathrm{T}$ test

33\%概算量之必要量 50\%概算量と必要量

I 群 有意差有 $(\mathrm{P}<0.01)$ 有意差有 $(\mathrm{P}<0.01)$

II 群 有意差有 $(\mathrm{P}<0.01)$ 有意差 無 $(\mathrm{P}<0.01)$
III 群 有意差有 $(P<0.01)$ 有意差 無 $(P<0.01)$ IV 群 有意差有 $(P<0.01)$ 有意差 無 $(P<0.01)$ $\mathrm{V}$ 群 有意差有 $(\mathrm{P}<0.01)$ 有意差 無 $(\mathrm{P}<0.01)$ VI群 有意差 無 $(P<0.01)$ 有意差 無 $(P<0.01)$ のようになった。

\section{体重群}

表 3 は体重 4 群の表である. 内容は，体外循環 時間群の表 1 と同様である.

体重 4 群のプロタミン必要量に対しての33\%概 算量, 50\%概算量の平均值でのグラフである(図5).

表 2 B LOOD使用群

\begin{tabular}{|c|c|c|c|c|c|c|c|c|c|c|}
\hline & 夜 & 月 & ${ }^{\mathrm{kg}}$ & $\begin{array}{c}\text { 分 } \\
\text { 体外循羁時間 } \\
\end{array}$ & $\begin{array}{c}\mathrm{mg} / \mathrm{kg} \text { 当 } \\
\text { Heparin }\end{array}$ & $\begin{array}{l}\mathrm{mg} / \mathrm{kg} \text { 当 } \\
\text { Protamin }\end{array}$ & $\mathrm{P} / \mathrm{H}$ 比 & $\begin{array}{l}\mathrm{mg} / \mathrm{kg} \text { 当 } \\
\mathrm{P} / \mathrm{H} 33 \%\end{array}$ & $\begin{array}{l}\mathrm{mg} / \mathrm{kg} \text { 当 } \\
\mathrm{P} / \mathrm{H} 50 \%\end{array}$ & 傮 項 \\
\hline I & $\begin{array}{c}0 m l \\
n=27\end{array}$ & $\begin{array}{c}87.89 \\
\pm 40.73\end{array}$ & $\begin{array}{r}24.59 \\
\pm 15.61\end{array}$ & $\begin{array}{c}29.96 \\
\pm 16.42\end{array}$ & $\begin{array}{c}3.07 \\
\pm 0.35\end{array}$ & $\begin{array}{c}2.29 \\
\pm 0.80\end{array}$ & $\begin{array}{c}0.77 \\
\pm 0.32\end{array}$ & $\begin{array}{l}1.01 \\
\pm 0.11\end{array}$ & $\begin{array}{c}1.53 \\
\pm 0.17\end{array}$ & \begin{tabular}{|c|}
$P / H \quad 77 \%$ \\
2.36 \\
\pm 0.27
\end{tabular} \\
\hline II & $\begin{array}{l}400 \mathrm{ml} \\
n=3\end{array}$ & $\begin{array}{c}63.67 \\
\pm 41.00\end{array}$ & $\begin{array}{c}15.93 \\
\pm 3.97\end{array}$ & $\begin{array}{c}85.00 \\
\pm 34.60\end{array}$ & $\begin{array}{c}3.83 \\
\pm 0.85\end{array}$ & $\begin{array}{c}1.77 \\
\pm 0.18\end{array}$ & $\begin{array}{c}0.49 \\
\pm 0.15\end{array}$ & $\begin{array}{l}1.26 \\
\pm 0.30\end{array}$ & $\begin{array}{c}1.92 \\
\pm 0.42\end{array}$ & $\begin{array}{c}\mathrm{P} / \mathrm{H} 49 \% \\
1.88 \\
\pm 0.42\end{array}$ \\
\hline III & $\begin{array}{l}600 \mathrm{ml} \\
n=18\end{array}$ & $\begin{array}{c}47.61 \\
\pm 42.69\end{array}$ & $\begin{array}{l}13.02 \\
\pm 5.55\end{array}$ & $\begin{array}{l}145.11 \\
\pm 87.54\end{array}$ & $\begin{array}{c}5.03 \\
\pm 1.12\end{array}$ & $\begin{array}{c}2.70 \\
\pm 0.64\end{array}$ & $\begin{array}{c}0.56 \\
\pm 0.17\end{array}$ & $\begin{array}{l}1.66 \\
\pm 0.37\end{array}$ & $\begin{array}{c}2.52 \\
\pm 0.56\end{array}$ & \begin{tabular}{|c|} 
P/H $56 \%$ \\
2.81 \\
\pm 0.63
\end{tabular} \\
\hline IV & $\begin{array}{l}800 \mathrm{ml} \\
\mathrm{n}=51\end{array}$ & $\begin{array}{c}30.88 \\
\pm 27.86\end{array}$ & $\begin{array}{l}10.44 \\
\pm 4.88\end{array}$ & $\begin{array}{l}78.39 \\
\pm 49.95\end{array}$ & $\begin{array}{c}4.98 \\
\pm 1.69\end{array}$ & $\begin{array}{c}2.63 \\
\pm 0.58\end{array}$ & $\begin{array}{c}0.56 \\
\pm 0.16\end{array}$ & $\begin{array}{c}1.65 \\
\pm 0.56\end{array}$ & $\begin{array}{r}2.56 \\
\pm 0.84\end{array}$ & $\begin{array}{c}\mathrm{P} / \mathrm{H} 56 \% \\
2.81 \\
\pm 0.94\end{array}$ \\
\hline $\mathrm{V}$ & $\begin{array}{l}1000 \mathrm{ml} \\
n=16\end{array}$ & $\begin{array}{r}41.69 \\
\pm 50.2\end{array}$ & $\begin{array}{l}11.49 \\
\pm 8.36\end{array}$ & $\begin{array}{c}132.00 \\
\pm 109.96\end{array}$ & $\begin{array}{c}7.10 \\
\pm 2.59\end{array}$ & $\begin{array}{l}3.20 \\
\pm 1.27\end{array}$ & $\begin{array}{c}0.48 \\
\pm 0.18\end{array}$ & $\begin{array}{c}2.34 \\
\pm 0.85\end{array}$ & $\begin{array}{c}3.52 \\
\pm 1.29\end{array}$ & $\begin{array}{c}P / H \quad 48 \% \\
3.40 \\
\pm 1.24\end{array}$ \\
\hline VI & $\begin{array}{l}1200 \mathrm{ml} \\
n=5\end{array}$ & $\begin{array}{c}54.60 \\
\pm 38.49\end{array}$ & $\begin{array}{l}13.18 \\
\pm 6.65\end{array}$ & $\begin{array}{l}140.60 \\
\pm 54.92\end{array}$ & $\begin{array}{c}7.89 \\
\pm 5.68\end{array}$ & $\begin{array}{c}1.94 \\
\pm 0.87\end{array}$ & $\begin{array}{c}0.33 \\
\pm 0.21\end{array}$ & $\begin{array}{c}2.61 \\
\pm 1.87\end{array}$ & $\begin{array}{c}3.95 \\
\pm 2.84\end{array}$ & $\begin{array}{c}P / H \quad 33 \% \\
2.61 \\
\pm 1.87\end{array}$ \\
\hline
\end{tabular}




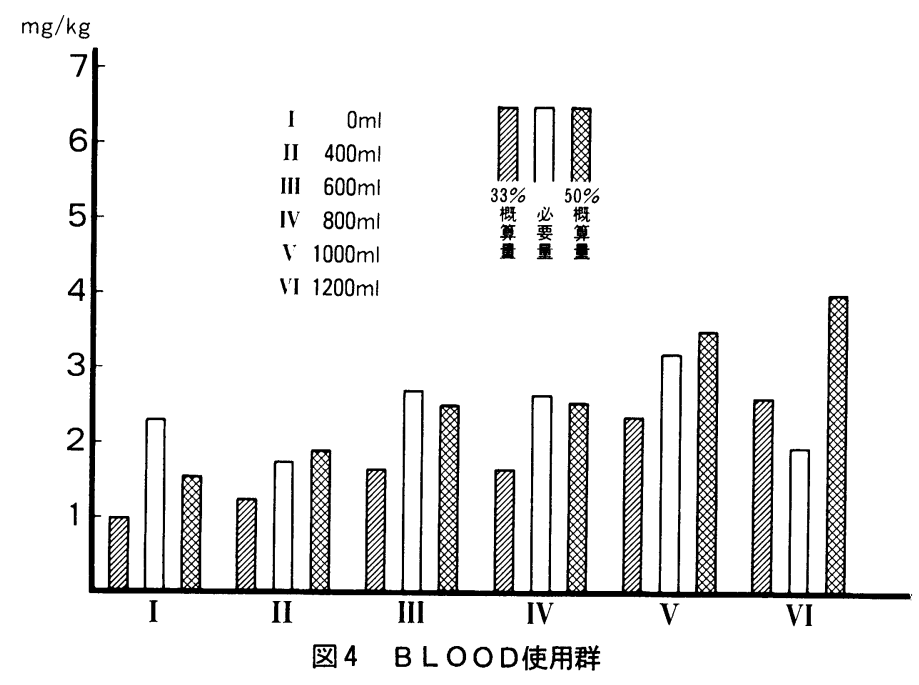

表 3 BODY WE I GHT群

\begin{tabular}{|c|c|c|c|c|c|c|c|c|c|c|}
\hline & $\begin{array}{l}\text { Body } \\
\text { Wight }\end{array}$ & 月 & 体 & 体外循睴時間 & $\begin{array}{c}\mathrm{mg} / \mathrm{kg} \text { 当 } \\
\text { Heparin }\end{array}$ & $\begin{array}{l}\mathrm{mg} / \mathrm{kg} \text { 当 } \\
\text { Protamin }\end{array}$ & $\mathrm{P} / \mathrm{H}$ 比 & $\begin{array}{l}\mathrm{mg} / \mathrm{kg} \text { 当 } \\
\mathrm{P} / \mathrm{H} 33 \%\end{array}$ & $\begin{array}{l}\mathrm{mg} / \mathrm{kg} \text { 当 } \\
\mathrm{P} / \mathrm{H} 50 \%\end{array}$ & 偳 項 \\
\hline$I_{n=47}$ & $\begin{array}{l}\text { 10kg } \\
\text { 以下 }\end{array}$ & $\begin{array}{c}13.00 \\
\pm 7.92\end{array}$ & $\begin{array}{c}6.97 \\
\pm 1.92\end{array}$ & $\begin{array}{c}93.00 \\
\pm 39.50\end{array}$ & $\begin{array}{c}6.57 \\
\pm 2.69\end{array}$ & $\begin{array}{c}2.81 \\
\pm 0.84\end{array}$ & $\begin{array}{c}0.46 \\
\pm 0.13\end{array}$ & $\begin{array}{c}2.17 \\
\pm 0.89\end{array}$ & $\begin{array}{c}3.29 \\
\pm 1.34\end{array}$ & $\begin{array}{c}\mathrm{P} / \mathrm{H} 46 \% \\
3.02 \\
\pm 1.24\end{array}$ \\
\hline $\begin{array}{l}\text { II } \\
n=32\end{array}$ & $\begin{array}{l}10.1 \mathrm{~kg} \\
15.0 \mathrm{~kg}\end{array}$ & $\begin{array}{c}43.00 \\
\pm 17.21\end{array}$ & $\begin{array}{c}13.01 \\
\pm 1.49\end{array}$ & $\begin{array}{c}81.78 \\
\pm 66.66\end{array}$ & $\begin{array}{c}4.21 \\
\pm 0.88\end{array}$ & $\begin{array}{c}2.57 \\
\pm 0.54\end{array}$ & $\begin{array}{c}0.63 \\
\pm 0.18\end{array}$ & $\begin{array}{c}1.39 \\
\pm 0.29\end{array}$ & $\begin{array}{c}2.11 \\
\pm 0.44\end{array}$ & $\begin{array}{c}P / H 63 \% \\
2.66 \\
\pm 0.56\end{array}$ \\
\hline $\begin{array}{l}\text { III } \\
n=21\end{array}$ & $\begin{array}{l}15.1 \mathrm{~kg} \\
\int_{20.0 \mathrm{~kg}}\end{array}$ & $\begin{array}{c}71.52 \\
\pm 16.89\end{array}$ & $\begin{array}{l}17.21 \\
\pm 1.40\end{array}$ & $\begin{array}{c}67.90 \\
\pm 61.16\end{array}$ & $\begin{array}{c}3.64 \\
\pm 0.86\end{array}$ & $\begin{array}{c}2.18 \\
\pm 0.70\end{array}$ & $\begin{array}{c}0.62 \\
\pm 0.23\end{array}$ & $\begin{array}{c}1.20 \\
\pm 0.28\end{array}$ & $\begin{array}{c}1.82 \\
\pm 0.43\end{array}$ & $\begin{array}{c}\mathrm{P} / \mathrm{H} 62 \% \\
2.25 \\
\pm 0.52\end{array}$ \\
\hline${ }_{n=20}^{I V}$ & $\underset{\text { 以上 }}{20.1 \mathrm{~kg}}$ & $\begin{array}{l}122.35 \\
\pm 33.38\end{array}$ & $\begin{array}{r}31.15 \\
\pm 15.19\end{array}$ & $\begin{array}{c}106.00 \\
\pm 137.75\end{array}$ & $\begin{array}{c}3.58 \\
\pm 1.26\end{array}$ & $\begin{array}{c}2.55 \\
\pm 1.12\end{array}$ & $\begin{array}{c}0.75 \\
\pm 0.35\end{array}$ & $\begin{array}{c}1.18 \\
\pm 0.41\end{array}$ & $\begin{array}{c}1.79 \\
\pm 0.63\end{array}$ & $\begin{array}{c}\mathrm{P} / \mathrm{H} 75 \% \\
2.68 \\
\pm 0.94\end{array}$ \\
\hline
\end{tabular}

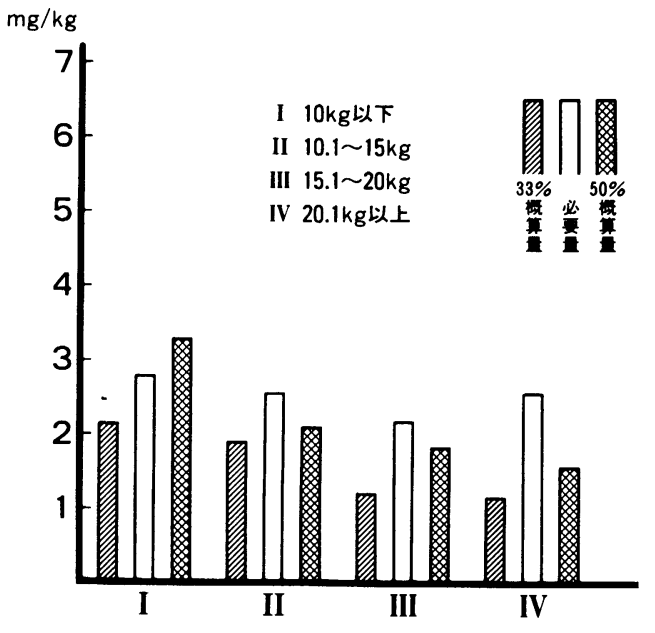

図5 BODY WE I GHT群
Studen T test では,

$33 \%$ 概算量之必要量 $50 \%$ 概算量之必要量

I群 有意差有 $(\mathrm{P}<0.01)$ 有意差 無 $(\mathrm{P}<0.01)$

II群 有意差有 $(\mathrm{P}<0.01)$ 有意差有 $(\mathrm{P}<0.01)$

III群 有意差有 $(\mathrm{P}<0.01)$ 有意差 無 $(\mathrm{P}<0.01)$

IV 群 有意差有 $(P<0.01)$ 有意差有 $(P<0.01)$

であった。

考 察

個々の体重kg当同一量のヘパリンを投与しても ヘパリンの感受性，半减期には個体差があり一定 の基準のあとにへパリン・プロタミンの投与量を 決定することは適当でない. 
しかし現実には，検査回数が増し容易でないた め, 基本的な投与規定を設けておく必要がある.

\section{プロタミン必要量について}

弓削 ${ }^{1} ら は, 4 \mathrm{mg} / \mathrm{kg}$ のプロタミン投与はヘパリン 総量の78\%に相当しへパリン中和効量には充分で あると報告し，佐藤 ${ }^{2}$ らは, ヘパリン総量の $88 \%$ で中和ができ, 1 2 時以内の体外循環であれば 初回 $4 \mathrm{mg} / \mathrm{kg}$ 追加 $/ \mathrm{mg} / \mathrm{kg} /$ 時のヘパリン投与方法 のとき，ヘパリン総投与量の $0.88 \times 1.07$ なわち 0.95倍のプロタミン量がヘパリン中和のための一 応の目安となると報告している。

今回の結果では, 120 症中プロタミン・ヘパリ ン使用総量比 1：1すなわち100\%以上の症例は $(1: 1)(1: 1.05)(1: 1.13)(1: 1.17)(1: 1.2)$ ( $1: 1.2)(1: 1.44)$ の 症例であった. 各群の内訳は：

体外循環時間

I群 23症例中 4 症例

II 群 27 症例中 2 症例

III 群 23 症例中 1 症例

充填時使用血液

I 群 27 症例中 7 症例 体重

II 群 32症例中 1 症例

江群 20症例中 6 症例 であった。

その他は全て 1 ：1以下で, 平均プロタミン,

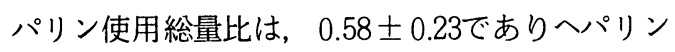

の使用状況が異なり各報告より低值を示したが, 納得のいくあのと考える.

\section{プロタミン概算量について}

早期へパリンの中和・止血目的には, 体外循環 終了直後プロタミン概算量の静注投与を行なうの はよい手段と考えている.

施設によってはへパリン使用総量の 1.5 倍また は 1.2 倍のプロタミン投与を行なっているのが多 く見られるが, 当施設では, 今後, ヘパリン使用 総量の 0.5 倍のプロタミン概算量投与でよいと考 えている.

\section{結 語}

1. プロタミン概算量 $33 \%$ では，プロタミン必要 量に対し差の大きい群が多い.

2. プロタミン概算量 $50 \%$ では，プロタミン必要 量に対し差が小さく值が接近している群が多 い.

3. プロタミン概算量の過剩投与症例は, 危険量 とは考えにくい.

\section{文 献}

1）弓削一郎ほか：胸部外科 $32 ： 5337-340$ 1979.

2）佐藤敏光ほか : 臨床麻酔 VOL 5/N0.11 1299 -13031981 . 